Review

\title{
Respiratory Syncytial Virus: Current Progress in Vaccine Development
}

\author{
Rajeev Rudraraju ${ }^{1}$, Bart G. Jones ${ }^{1}$, Robert Sealy ${ }^{1}$, Sherri L. Surman ${ }^{1}$ \\ and Julia L. Hurwitz ${ }^{1,2, *}$
}

1 Department of Infectious Diseases, St. Jude Children's Research Hospital, 262 Danny Thomas Place, Memphis, TN 38105, USA; E-Mails: Rajeev.rudraraju @stjude.org (R.R.); bart.jones@stjude.org (B.J.); robert.sealy@stjude.org (R.S.); sherri.surman@stjude.org (S.S.) Department of Microbiology, Immunology and Biochemistry, University of Tennessee Health Science Center, 858 Madison Avenue, Memphis, TN 38163, USA

* Author to whom correspondence should be addressed; E-Mail: julia.hurwitz@ stjude.org; Tel.: +1-901-595-2464; Fax: +1-901-595-3099.

Received: 16 January 2013; in revised form: 1 February 2013 / Accepted: 4 February 2013 / Published: 5 February 2013

\begin{abstract}
Respiratory syncytial virus (RSV) is the etiological agent for a serious lower respiratory tract disease responsible for close to 200,000 annual deaths worldwide. The first infection is generally most severe, while re-infections usually associate with a milder disease. This observation and the finding that re-infection risks are inversely associated with neutralizing antibody titers suggest that immune responses generated toward a first RSV exposure can significantly reduce morbidity and mortality throughout life. For more than half a century, researchers have endeavored to design a vaccine for RSV that can mimic or improve upon natural protective immunity without adverse events. The virus is herein described together with the hurdles that must be overcome to develop a vaccine and some current vaccine development approaches.
\end{abstract}

Keywords: respiratory syncytial virus; candidate vaccines; protective immunity 


\section{RSV, the Virus}

Respiratory syncytial virus is a negative strand RNA virus in the family Paramyxoviridae, the subfamily Pneumovirinae and the genus Pneumovirus. RSV was first discovered in 1952 as the cause of a serious lower respiratory tract disease, most pronounced among children in their first year of life [1]. Other individuals who are susceptible to severe RSV disease include patients with cardiac and pulmonary disorders, patients with immunodeficiencies, and the elderly [2-6]. RSV infection generally presents as an upper respiratory tract (URT) infection which progresses for several days before virus traffics to the lung [1,7]. Most infants are able to clear virus without extreme adverse events, but in the United States approximately $2 \%$ require hospitalization [8,9]. Globally, RSV infections are estimated to result in up to 199,000 deaths annually in children younger than 5 years of age [10] and treatment options remain controversial. Re-infections can occur, but generally result in milder disease; risks of infection are inversely associated with RSV-specific serum neutralizing antibody titers [11,12]. For infants at risk for first infections, the passive transfer of monoclonal RSV F-specific antibodies is recommended, but this type of prophylaxis is expensive and unavailable for most individuals who need it [13]. A licensed vaccine, the single best health care solution to infectious disease, is unavailable in the RSV field.

The RSV genome consists of 11 coding sequences including NS1, NS2, N, P, M, SH, G, F, M2-1, M2-2 and L [1,14]. The predominant proteins on the outer membrane of the mature virus are G, F and SH. Initiation of infection is usually mediated by the interaction between RSV G, the major attachment glycoprotein, and the host cell membrane. The viral receptors for $G$ (and F) proteins on mammalian cells are not fully defined, but $G$ can bind highly sulfated heparin-like glycosaminoglycans [15] as well as the CX3CR1 fracktalkine chemokine receptor [16]. G attachment facilitates F-mediated membrane fusion, although $\mathrm{F}$ protein can bind cell membranes independently (e.g., via binding to cellular heparan sulfate and nucleolin [16,17]) and mediate virus infection in the absence of $G[1,18]$. Fusion occurs when the $F 1$ subunit of $F$ protein is inserted into the target membrane and the protein refolds into a hairpin structure bringing virus and cell membranes into close proximity [19]. Upon membrane fusion, virus material including a single negative strand RNA genome is released into the cell cytoplasm [19]. Viral RNA is then transcribed and replicated yielding viral mRNA and new virus genome. New virions are assembled at the cell membrane, bud using cell membranes as their outer coat, and then target new cells for additional rounds of infection. Non-structural proteins support virus production while down-regulating host cell growth and defense mechanisms [1].

\section{Hurdles to Vaccine Development}

A main hurdle for RSV vaccine development was encountered in the 1960s during the testing of a formalin-inactivated RSV vaccine (FI-RSV). Unfortunately, the vaccinated infants were not protected from RSV infection. Instead, an unusually large percentage of the vaccinated children, when subsequently exposed to RSV by natural causes, developed disease severe enough to require hospitalization and there were two vaccine-related deaths [20]. It is essential that such a scenario never be repeated, and because the reason for the vaccine-related adverse events has not been confirmed, 
scientists are unsure precisely how to proceed. There remains no licensed vaccine product after onehalf century of additional research.

The cause of vaccine-related deaths remains a point of discussion. One potential explanation is as follows: The formalin treatment of RSV altered membrane proteins on the virus and in so doing, rendered a vaccine that induced antibody responses that were non-neutralizing [21,22]. The inactivated vaccine also failed to elicit robust CD8+ T cells, because these classical killers of virus-infected targets are best induced by endogenously expressed viral antigens. In the absence of robust neutralizing antibodies and CD8+ T cells, RSV persisted and induced an aggressive CD4+ T cell and cytokine response in the lower respiratory tract [23,24]. Uncontrolled RSV replication and persistent inflammation led to blockage of the small airways in infants, leading to substantial morbidity and mortality $[1,4,14,25]$.

There is now debate as to which immune cell populations or effector molecules were responsible for disease [21,26-33]. In a murine model designed to recapitulate the clinical outcome with FI-RSV, it was demonstrated that a subset of RSV G-specific CD4+ Th2 cells and eosinophils associated with disease. [23,24,31,32,34,35]. Additional mouse experiments showed that inhibition of IL-4 and IL-10 Th2 cytokines abrogated pulmonary histopatholgy [24]. Some researchers argue that the induction of Th2 cells, or perhaps the induction of any RSV-specific T cells should be avoided [36], even though $\mathrm{T}$ cells may be key providers of help for B cells and cytotoxic $\mathrm{T}$ lymphocyte functions at the time of RSV exposure. Others argue that the large majority of granulocytes described in original clinical autopsy reports were neutrophils rather than eosinophils [37], questioning the absolute comparison between mouse and human responses to FI-RSV. The potential benefits provided under the appropriate conditions by $\mathrm{Th} 2$ cells, other CD4+ and CD8+ $\mathrm{T}$ cell subsets, and eosinophil populations are contemplated [37-42]. For example, it is noted that individuals who lack $\mathrm{T}$ cells can experience great difficulty in RSV clearance and suffer worse outcomes than their immunocompetent counterparts $[4,14,43,44]$. It is further noted that eosinophils can be beneficial in that their transfer to the lungs of RSV-infected mice can enhance RSV clearance and inhibit airway hyper-reactivity [45]. Until debates are resolved, researchers and regulatory boards struggle to define 'go' and 'no go' criteria for the advancement of candidate vaccines, particularly when clinical studies target the pediatric arena. It is possible that past RSV vaccine candidates may have proved safe and efficacious in children, but were never tested in seronegative, pediatric populations. Perhaps a solution resides in comprehensive data analyses, revealing the complexities of the immune system and that each lymphocyte subset need not be categorically designated as beneficial or injurious [46]. Rather, as is the case in most RSV-experienced adults, a variety of adaptive and innate immune effectors including B cells, CD4+ T helper cells and CD8+ cytotoxic T lymphocytes function synergistically to mediate safe elimination of virus and virus-infected cells.

Another issue pertinent to RSV vaccine development concerns the selection of an appropriate human test population. Vaccine studies in young infants are performed with hesitancy due to the devastating experience with the FI-RSV vaccine. One suggested possibility is that vaccines might be tested in seropositive adults including the elderly rather than in infants. A number of strategies are considered including: (i) standard vaccination of placebo and control groups with subsequent assessment of disease caused by natural RSV exposure, (ii) the use of an experimental RSV challenge virus [47], and (iii) the vaccination of pregnant females to measure protection afforded to the infant at 
birth. One or more of these strategies may prove fruitful provided that attention is paid to a number of confounding variables. First, due to varying degrees of seropositivity in older individuals, immune responsiveness toward vaccination may be difficult to interpret. Individuals with high pre-existing immunity might be expected to show a boost in antibody titers following vaccination, but may instead clear vectors and antigens so rapidly that there is little opportunity for immune cells to re-activate. Second, vaccine safety data may be difficult to interpret due to frequent, unrelated disease complications in the oldest adults. One additional variable to be considered (upon design of either pediatric or adult vaccine protocols) is that individuals with poor diets or poor metabolism (e.g., vitamin deficiency) may exhibit general defects in immune responses toward respiratory virus vaccines $[48,49]$. With these considerations in mind, it has been proposed that RSV vaccine studies in the elderly are feasible, but would require the recruitment of thousands of participants to ensure fair vaccine assessment [50]. Another recent proposal has been that RSV vaccine studies might best be conducted not in the youngest infants or in adults, but in seronegative children who are at least 6 months of age [51]. Perhaps efficacy studies in older, seronegative children could assist vaccine licensure for a restricted age group while prompting additional clinical studies in the youngest infants.

\section{Current RSV Vaccine Strategies}

The first formal vaccine development effort occurred two centuries ago when Edward Jenner demonstrated that material from a cowpox lesion could serve as a vaccine for smallpox [52]. Successful vaccination, both then and now, relies on the safe introduction of a pathogen's antigenic determinants to the immune system. If the vaccine's antigenic determinants are well matched to those of the native pathogen (as was the case for cowpox and smallpox), the antigens will activate pathogen-specific lymphocytes. In the case of virus-specific B cells, some effectors will mature to the plasma cell stage and constitutively secrete antibodies into blood, lymph and mucosal secretions, while others will maintain memory status, capable of immediate re-activation upon pathogen exposure. Activated CD8+ T cells are classically known for their killing of virus infected cells, while CD4+ T cells, (including Th1, Th2, Th17, TFh, Treg, and other subsets) are known for their support and regulation of $\mathrm{CD} 8+$ and $\mathrm{B}$ cell activities [53-57]. The heightened or "primed" state of immune surveillance may last months or years to inhibit pathogen entry and pathogen-mediated damage to the host [58]. Generally, vaccines are developed by: (i) inactivating the virus, (ii) identifying a related virus in another species that is safe in humans (the Jennerian approach), (iii) attenuating the virus, or (iv) using recombinant technology to present viral antigens, often in the context of a replication competent or replication-incompetent vector. In the RSV vaccine field, because of the outcome of the FI-RSV vaccine study, the first approach is generally discouraged, even if candidate vaccines retain RSV neutralizing determinants. The second strategy, the Jennerian approach, has not been advanced due to an insufficient antigenic match between bovine and human RSV [59]. The third and fourth strategies are the topics of most current vaccine research, described in greater detail below. Preclinical testing of vaccine candidates is generally accomplished first in small animals and then in non-human primates. Most small animal studies use hamsters, BALB/c mice, or cotton rats [60-63] while non-human primate studies generally use African green monkeys, rhesus macaques and chimpanzees [64-66]. Each animal is at least semi-permissive for RSV infection and is therefore 
advantageous in that immune responses and immunopathological events can be measured, but no animal model fully predicts the course of immune responses and disease in humans. In one instance, for example, an attenuated RSV vaccine appeared to be safe in non-human primates, but proved unsafe when tested in seronegative children [67]. Again, the debates described above concerning: (i) interpretation of data from animal experiments, and (ii) selection of clinical trial target populations, must be considered to determine when and how to advance vaccine candidates from pre-clinical to clinical trials.

\subsection{Attenuated Virus Vaccines: Testing Variant Mutations}

One strategy for RSV vaccine development has been to attenuate virus by cold adaption [68,69]. An early product of this research was cpts-248/404 [70,71]. However, in the youngest infants, the vaccine caused URT congestion associated with peak virus recovery and was deemed unacceptable for further development. More recently the cpts-248/404/1030/ $\mathrm{SH}$ vaccine was developed by introducing further mutations and deleting the $\mathrm{SH}$ gene, resulting in a more satisfactory product [72]. In a recent clinical study with this candidate, post-vaccination nasal washes revealed viruses with partial loss of the temperature sensitive phenotype, often due to a tyrosine/asparagine substitution in the L gene at position 1321 [73]. Researchers corrected the problem by creating a reversion-resistant virus with an alternative attenuating codon at position 1321. However, they then discovered a compensatory mutation at position 1313, forcing a deletion of that position $(\Delta 1313)$ to yield a safer vaccine. When the $\Delta 1313$ deletion was paired with an NS2 gene deletion and tested at incrementally increasing temperatures, another compensatory mutation was discovered, I1314T. Finally, a vaccine with a new combination of mutations ( $\Delta \mathrm{NS} 2 / \Delta 1313 / 1314 \mathrm{~L})$ is being developed for evaluation in phase I clinical trials [74]. Reverse genetics, a powerful technology that allows the manipulation of viral genomes and recovery of infectious, recombinant virus particles, has assisted the progress described above [75].

A number of attenuated RSV vaccines have now been tested clinically. Currently, a phase I clinical study in adults, seropositive children and seronegative children is in progress to test safety and immunogenicity of an intranasally (I.N.) delivered RSV M2-2 deletion mutant [73,76,77].

The development of live-attenuated vaccines presents significant challenges, particularly when vaccines are delivered by the respiratory route to neonates. A concern is that viruses with compensatory mutations in the live-attenuated vaccines may associate with reversion to pathogenic phenotypes and lead to increased frequencies of adverse reactions in vivo. There is also a difficulty related to manufacturing and distribution, as RSV is naturally sensitive to changes in temperature, and attenuated strains by definition are difficult to propagate to high titers.

\subsection{Recombinant Protein Vaccines}

Recombinant technology provides great flexibility both in terms of the RSV antigen(s) and the vector(s) with which the antigen is expressed. The major target antigens of recombinant vaccine technology are RSV G and F, as these are each capable of eliciting neutralizing antibodies as well as T cell responses. $\mathrm{F}$ is particularly attractive due to its considerable conservation among RSV isolates. Another antigen of recent interest is the small hydrophobic protein, SH [78]. 
As an example of progress in recombinant vaccine technology, Novartis is developing a postfusion RSV F trimer that elicits neutralizing antibodies and protection against RSV challenge in cotton rats [79]. Most researchers strive to match vaccine protein with pathogen protein to take advantage of polyclonal $\mathrm{B}$ and $\mathrm{T}$ cell responses that can work in unison to recognize and combat pathogen. Other researchers target particular epitopes such as a central conserved region of the $\mathrm{G}$ protein that induces antibodies to block the CX3C-CX3CR1 interaction. Mice vaccinated with fragments containing the $\mathrm{CX} 3 \mathrm{C}$ motif have been shown to generate immune responses that can reduce lung virus titers and pulmonary inflammation following RSV challenge [80]. Still other researchers, as described above, propose that all $\mathrm{T}$ cell epitopes (and many $\mathrm{B}$ cell epitopes) should be removed from RSV vaccines [36,42]. Using computational design, epitope-scaffold vaccines have been developed to mimic an individual epitope on the $\mathrm{F}$ protein known to correspond with a neutralizing monoclonal antibody activity (motavizumab, [13]). In one case, several scaffolds were developed based on 13 discontinuous RSV F contact residues (xSxxLSxINDxxxxNDxKKLxSNx) for motavizumab. An automated search of protein structures supported the selection of three proteins as scaffolds: protein Z, a domain of protein A from Staphylococcus aureus, Cag-Z from Helicobacter pylori and the p26 capsid protein from equine infectious anemia virus. Amino acids outside of the motavizumab epitope were then modified or removed to optimize stability, solubility and motavizumab binding affinity. Critical to decisions concerning scaffold design are demonstrations that $\mathrm{B}$ cell and $\mathrm{T}$ cell determinants on viruses are often dependent on structural and spatial context, as regions outside the epitope affect 3-dimensional folding, post-translational modifications, and antigen processing [81-84]. For this reason, immune cells that respond to a protein fragment in one context (e.g., vaccine) do not necessarily recognize the same fragment when the context is changed (e.g., virus). When the Stapylococcus aureus protein A scaffold was fused to a pan-HLA DR binding epitope and tested for immunogenicity in mice, it induced RSV-binding antibodies, but these antibodies failed to neutralize RSV [36]. A separate study of a motavizumab-based scaffold in non-human primates illustrated neutralizing antibodies in a fraction of animals [85].

Most protein vaccines, whether designed to match unmanipulated viral proteins or targeted determinants, are combined with adjuvants. A plethora of adjuvants now exist including $\mathrm{W}_{80} 5 \mathrm{EC}$ [86], alum, 3-O-desacyl-4'-monophosphoryl lipid A (MPL), muramyl dipeptide (MDP), natural host defense peptides, $\mathrm{CpG}$ oligodeoxynucleotides (ODN) and polyphosphazenes. Polyphosphazenes are synthetic water-soluble polymers containing an inorganic backbone of alternating phosphorus and nitrogen atoms. Adjuvants are in some cases known to trigger cell molecules (e.g., toll-like receptors, TLR) to activate innate and adaptive immune responses. For example, MPL, CpG ODN, and MDP are ligands for TLR-4, TLR-9, and NOD2, respectively. The $\mathrm{W}_{80} 5 \mathrm{EC}$ product can serve both as an adjuvant and as a virus-inactivation method [86]. While adjuvant choices are many, U.S. Food and Drug Administration (FDA)-approved and licensed adjuvants are limited (alum and MPL). There is also a large variety of combinations for formulations of liposomes, nanoparticles or microparticles (synthetic particles and/or particles encompassing bacterial or viral components [87]) for the delivery of RSV proteins, peptides, and/or adjuvants. As an example, a truncated, secreted, trimeric F protein has been formulated for I.N. delivery with combinations of a TLR agonist (CpG ODN), an innate defense regulator peptide (IDR1002-VQRWLIVWRIRK), and polyphosphazene as nano- or microparticles, to induce RSV protective immunity [88,89]. Yet another example is Novavax's 
near-full length $\mathrm{F}$ glycoprotein formulated as a nanoparticle vaccine. This vaccine has been tested in healthy adults and has been shown to induce significant increases in the anti-F antibody response, including micro-neutralizing activities and competitive activity against the neutralizing monoclonal antibody Palivizumab [13,90-92]. An additional use of adjuvant has been with MPL combined not with a recombinant protein or particle, but with virosomes comprising membranes from RSV [93].

\subsection{Replication Competent, Recombinant Viral Vaccines}

Reverse genetics has assisted the development of recombinant viral vaccines that can serve as delivery systems for RSV antigens. One such vaccine, which has been well advanced in clinical trials, is MedImmune's MEDI-534 [94,95]. This vaccine is a replication-competent vaccine that expresses RSV F [75,96]. The backbone is based on a bovine parainfluenza virus type 3 with substituted human PIV3 F and HN glycoproteins. MEDI-534 was tested in non-human primates and also in a phase I study in young children between the ages of 6 months and $<24$ months. Doses of 10,000, 100,000 and $1,000,000 \mathrm{TCID}_{50}$ were tested in the clinical trial and RSV specific antibody responses were noted in $50 \%$ of vaccinees administered three $1,000,000$ TCID $_{50}$ doses of vaccine with two month intervals. Virus that was shed from study participants revealed genetic changes that were associated with reduced RSV F protein expression. A close analysis of the MEDI-534 vaccine then demonstrated that some of the same genetic variants were minor components of the administered vaccine [97]. The implication of these sequence variants is a current topic of discussion.

Another promising candidate is St. Jude's recombinant, replication competent vaccine (SeVRSV), also developed with reverse genetics technology [75]. Sendai virus (SeV), a mouse parainfluenza virus type I with a high sequence and antigenic similarity to human parainfluenza virus type I (hPIV-1), was used as the vaccine's backbone [98-102]. $\mathrm{SeV}$ is an attractive vaccine candidate and vaccine backbone, because there has never been a confirmed case of $\mathrm{SeV}$-associated disease in humans. The species specificity of Sendai virus is attributed in part to its unique sensitivity to human type I interferon [103]. In small animals a single I.N. dose of SeV induced B and T cell responses within days after immunization that lasted for the animal's lifetime without need for a booster [62]. The SeVRSV recombinant carries the RSV F gene and thereby instructs its expression in infected cells [104]. When tested in cotton rats, SeVRSV protected animals from challenge with both A and B RSV isolates. SeVRSV could also be mixed with two additional SeV-based vaccines in a single I.N. inoculation to protect against four different challenge viruses: RSV, hPIV-1, hPIV-2 and hPIV-3 [62]. When SeVRSV was tested as a vaccine in African green monkeys with non-recombinant $\mathrm{SeV}$ as a control, it safely and fully prevented infection of the lower airways following RSV challenge [66]. The non-recombinant $\mathrm{SeV}$ has already entered clinical trials as a hPIV-1 vaccine and has been well tolerated in adults [105] and 3-6 year old children. SeVRSV is now being manufactured for testing in an age de-escalation clinical trial. Previous pre-clinical and clinical data suggest that SeVRSV will safely protect children from both RSV and hPIV-1 infections. When compared to the live-attenuated RSV vaccines, $\mathrm{SeV}$ based vaccines benefit from their relative stability to temperature changes and ease of growth to high titers in chicken eggs and cell cultures, a boon for manufacturing and vaccine distribution. 


\subsection{A Variety of new Vectors and Concepts in the RSV Vaccine Field}

A great number of additional recombinant vaccines are in stages of pre-clinical testing. Vectors include Semliki Forest virus [106], Venezuelan equine encephalitis virus [107,108], adenovirus from humans or non-human primates [109,110], influenza virus [111], measles virus [112], Newcastle disease virus like particles (VLPs [113]) and plasmid DNA [114,115]. Other vaccine delivery systems are based not on viruses, but bacteria, yeast or plants [116], such as the Mucosis SynGEM® vaccine, an I.N. vaccine that presents native trimeric F protein formulated in a non-living bacterium-like particle (BLP) [117]. There have also been combination prime-boost strategies using one form of recombinant vaccine followed by another. For example a recombinant vaccine prime based on replication-defective chimpanzee adenovirus can be followed with a boost based on modified vaccinia Ankara (MVA) [118], or a recombinant DNA prime can be followed by recombinant adenoviral vector boosts [119]. This article describes a portion, but not all of the vaccine candidates that are currently under investigation. Table 1 provides a short list as a sampling of vaccine strategies with references and review articles. It is quite likely that one or more than one of the current vaccine candidates will prove successful. The advanced development and licensure of a safe and effective RSV vaccine will indeed be momentous, a long-awaited milestone for the prevention of the significant sickness and death caused by RSV infections.

Table 1. Sample respiratory syncytial virus (RSV) vaccine references and review articles.

\begin{tabular}{ll}
\hline Vaccine Type & Sample references \\
\hline & \\
Attenuated RSV & {$[73,74]$} \\
Inactivated RSV & {$[86,120]$} \\
RSV protein(s) adjuvanted and/or as micro/nano-particles & {$[79,89]$} \\
Epitope scaffold & {$[36]$} \\
Virosome & {$[93,121]$} \\
Virus like particle (VLP) & {$[113,122]$} \\
Replication competent virus-based vector & {$[66,94,95,97]$} \\
Bacteria-based vector & {$[123-125]$} \\
Plant-based vector & {$[116]$} \\
Prime-boost with heterologous vectors & {$[118,119]$.} \\
& \\
Related review articles & {$[\mathbf{1 , 4 , 1 4 , 2 5 , 1 1 5 , 1 2 6 ]}$} \\
\hline
\end{tabular}

\section{Acknowledgments}

This work was supported in part by NIH, NIAID grants P01-AI-054955, R01-AI088729, and R01AI78819, NCI grant P30-CA21765 and the American Lebanese Syrian Associated Charities. Acknowledgement is given to S. Varga, N. Lukacs and K. Harrod for organizing the 8th International Respiratory Syncytial Virus Symposium in 2012. 


\section{Conflict of Interest}

JLH is a co-author of a patent application relevant to SeVRSV vaccine development.

\section{References}

1. Collins, P.L.; Crowe, J.E. Respiratory Syncytial Virus and Metapneumovirus. In Fields Virology, 5th Edition; Knipe, D.M., Howley, P.M, Griffin, D.E., Lamb, R.A., Martin, M.A., Roizman B., et al., Eds; Lippincott Williams\&Wilkins: Philadelphia, PA, USA, 2007; pp. 1601-1646.

2. Groothuis, J.R.; Gutierrez, K.M.; Lauer, B.A. Respiratory syncytial virus infection in children with bronchopulmonary dysplasia. Pediatrics 1988, 82, 199-203.

3. Falsey, A.R.; Hennessey, P.A.; Formica, M.A.; Cox, C.; Walsh, E.E. Respiratory syncytial virus infection in elderly and high-risk adults. N. Engl. J. Med. 2005, 352, 1749-1759.

4. Collins, P.L.; Melero, J.A. Progress in understanding and controlling respiratory syncytial virus: Still crazy after all these years. Virus Res. 2011, 162, 80-99.

5. El Saleeby, C.M.; Somes, G.W.; DeVincenzo, J.P.; Gaur, A.H. Risk factors for severe respiratory syncytial virus disease in children with cancer: the importance of lymphopenia and young age. Pediatrics 2008, 121, 235-243.

6. Madhi, S.A.; Schoub, B.; Simmank, K.; Blackburn, N.; Klugman, K.P. Increased burden of respiratory viral associated severe lower respiratory tract infections in children infected with human immunodeficiency virus type-1. J. Pediatr. 2000, 137, 78-84.

7. Wright, P.F.; Gruber, W.C.; Peters, M.; Reed, G.; Zhu, Y.; Robinson, F.; Coleman-Dockery, S.; Graham, B.S. Illness severity, viral shedding, and antibody responses in infants hospitalized with bronchiolitis caused by respiratory syncytial virus. J. Infect. Dis. 2002, 185, 1011-1018.

8. Zhou, H.; Thompson, W.W.; Viboud, C.G.; Ringholz, C.M.; Cheng, P.Y.; Steiner, C.; Abedi, G.R.; Anderson, L.J.; Brammer, L.; Shay, D.K. Hospitalizations associated with influenza and respiratory syncytial virus in the United States, 1993-2008. Clin. Infect. Dis. 2012, $54,1427-1436$.

9. Thompson, W.W.; Shay, D.K.; Weintraub, E.; Brammer, L.; Cox, N.; Anderson, L.J.; Fukuda, K. Mortality associated with influenza and respiratory syncytial virus in the United States. JAMA 2003, 289, 179-186.

10. Nair, H.; Nokes, D.J.; Gessner, B.D.; Dherani, M.; Madhi, S.A.; Singleton, R.J.; O'Brien, K.L.; Roca, A.; Wright, P.F.; Bruce, N.; et al. Global burden of acute lower respiratory infections due to respiratory syncytial virus in young children: a systematic review and meta-analysis. Lancet 2010, 375, 1545-1555.

11. Glezen, W.P.; Taber, L.H.; Frank, A.L.; Kasel, J.A. Risk of primary infection and reinfection with respiratory syncytial virus. Am. J. Dis. Child. 1986, 140, 543-546.

12. Shinoff, J.J.; O'Brien, K.L.; Thumar, B.; Shaw, J.B.; Reid, R.; Hua, W.; Santosham, M.; Karron, R.A. Young infants can develop protective levels of neutralizing antibody after infection with respiratory syncytial virus. J. Infect. Dis. 2008, 198, 1007-1015.

13. Fernandez, P.; Trenholme, A.; Abarca, K.; Griffin, M.P.; Hultquist, M.; Harris, B.; Losonsky, G.A. A phase 2, randomized, double-blind safety and pharmacokinetic assessment of 
respiratory syncytial virus (RSV) prophylaxis with motavizumab and palivizumab administered in the same season. BMC. Pediatr. 2010, 10, 38.

14. Collins, P.L.; Graham, B.S. Viral and host factors in human respiratory syncytial virus pathogenesis. J. Virol. 2008, 82, 2040-2055.

15. Feldman, S.A.; Hendry, R.M.; Beeler, J.A. Identification of a linear heparin binding domain for human respiratory syncytial virus attachment glycoprotein G. J. Virol. 1999, 73, 6610-6617.

16. Harcourt, J.L.; Karron, R.A.; Tripp, R.A. Anti-G protein antibody responses to respiratory syncytial virus infection or vaccination are associated with inhibition of $\mathrm{G}$ protein CX3C-CX3CR1 binding and leukocyte chemotaxis. J. Infect. Dis. 2004, 190, 1936-1940.

17. Tayyari, F.; Marchant, D.; Moraes, T.J.; Duan, W.; Mastrangelo, P.; Hegele, R.G. Identification of nucleolin as a cellular receptor for human respiratory syncytial virus. Nat. Med. 2011, 17, 1132-1135.

18. Techaarpornkul, S.; Collins, P.L.; Peeples, M.E. Respiratory syncytial virus with the fusion protein as its only viral glycoprotein is less dependent on cellular glycosaminoglycans for attachment than complete virus. Virology 2002, 294, 296-304.

19. Russell, C.J.; Luque, L.E. The structural basis of paramyxovirus invasion. Trends Microbiol. 2006, 14, 243-246.

20. Chin, J.; Magoffin, R.L.; Shearer, L.A.; Schieble, J.H.; Lennette, E.H. Field evaluation of a respiratory syncytial virus vaccine and a trivalent parainfluenza virus vaccine in a pediatric population. Am. J. Epidemiol. 1969, 89, 449-463.

21. Murphy, B.R.; Prince, G.A.; Walsh, E.E.; Kim, H.W.; Parrott, R.H.; Hemming, V.G.; Rodriguez, W.J.; Chanock, R.M. Dissociation between serum neutralizing and glycoprotein antibody responses of infants and children who received inactivated respiratory syncytial virus vaccine. J. Clin. Microbiol. 1986, 24, 197-202.

22. Murphy, B.R.; Walsh, E.E. Formalin-inactivated respiratory syncytial virus vaccine induces antibodies to the fusion glycoprotein that are deficient in fusion-inhibiting activity. J. Clin. Microbiol. 1988, 26, 1595-1597.

23. Varga, S.M.; Wang, X.; Welsh, R.M.; Braciale, T.J. Immunopathology in RSV infection is mediated by a discrete oligoclonal subset of antigen-specific CD4(+) T cells. Immunity. 2001, 15, 637-646.

24. Connors, M.; Giese, N.A.; Kulkarni, A.B.; Firestone, C.Y.; Morse, H.C., III; Murphy, B.R. Enhanced pulmonary histopathology induced by respiratory syncytial virus (RSV) challenge of formalin-inactivated RSV-immunized BALB/c mice is abrogated by depletion of interleukin-4 (IL-4) and IL-10. J. Virol. 1994, 68, 5321-5325.

25. Blanco, J.C.; Boukhvalova, M.S.; Shirey, K.A.; Prince, G.A.; Vogel, S.N. New insights for development of a safe and protective RSV vaccine. Hum. Vaccin. 2010, 6, 482-492.

26. Delgado, M.F.; Coviello, S.; Monsalvo, A.C.; Melendi, G.A.; Hernandez, J.Z.; Batalle, J.P.; Diaz, L.; Trento, A.; Chang, H.Y.; Mitzner, W.; et al. Lack of antibody affinity maturation due to poor Toll-like receptor stimulation leads to enhanced respiratory syncytial virus disease. Nat. Med. 2009, 15, 34-41. 
27. Shaw, C.A.; Otten, G.; Wack, A.; Palmer, G.A.; Mandl, C.W.; Mbow, M.L.; Valiante, N.; Dormitzer, P.R. Antibody affinity maturation and respiratory syncytial virus disease. Nat. Med. 2009, 15, 725-726.

28. Polack, F.P.; Teng, M.N.; Collins, P.L.; Prince, G.A.; Exner, M.; Regele, H.; Lirman, D.D.; Rabold, R.; Hoffman, S.J.; Karp, C.L.; et al. A role for immune complexes in enhanced respiratory syncytial virus disease. J. Exp. Med. 2002, 196, 859-865.

29. Polack, F.P. Atypical measles and enhanced respiratory syncytial virus disease (ERD) made simple. Pediatr. Res. 2007, 62, 111-115.

30. Kakuk, T.J.; Soike, K.; Brideau, R.J.; Zaya, R.M.; Cole, S.L.; Zhang, J.Y.; Roberts, E.D.; Wells, P.A.; Wathen, M.W. A human respiratory syncytial virus (RSV) primate model of enhanced pulmonary pathology induced with a formalin-inactivated RSV vaccine but not a recombinant FG subunit vaccine. J. Infect. Dis. 1993, 167, 553-561.

31. Walzl, G.; Matthews, S.; Kendall, S.; Gutierrez-Ramos, J.C.; Coyle, A.J.; Openshaw, P.J.; Hussell, T. Inhibition of T1/ST2 during respiratory syncytial virus infection prevents T helper cell type 2 (Th2)- but not Th1-driven immunopathology. J. Exp. Med. 2001, 193, 785-792.

32. Rosenberg, H.F.; Dyer, K.D.; Domachowske, J.B. Respiratory viruses and eosinophils: Exploring the connections. Antiviral Res. 2009, 83, 1-9.

33. Becker, Y. Respiratory syncytial virus (RSV) evades the human adaptive immune system by skewing the Th1/Th2 cytokine balance toward increased levels of Th2 cytokines and IgE, markers of allergy - a review. Virus Genes 2006, 33, 235-252.

34. Srikiatkhachorn, A.; Braciale, T.J. Virus-specific CD8+ T lymphocytes downregulate T helper cell type 2 cytokine secretion and pulmonary eosinophilia during experimental murine respiratory syncytial virus infection. J. Exp. Med. 1997, 186, 421-432.

35. Legg, J.P.; Hussain, I.R.; Warner, J.A.; Johnston, S.L.; Warner, J.O. Type 1 and type 2 cytokine imbalance in acute respiratory syncytial virus bronchiolitis. Am. J Respir. Crit. Care Med. 2003, 168, 633-639.

36. McLellan, J.S.; Correia, B.E.; Chen, M.; Yang, Y.; Graham, B.S.; Schief, W.R.; Kwong, P.D. Design and characterization of epitope-scaffold immunogens that present the motavizumab epitope from respiratory syncytial virus. J Mol. Biol. 2011, 409, 853-866.

37. Prince, G.A.; Curtis, S.J.; Yim, K.C.; Porter, D.D. Vaccine-enhanced respiratory syncytial virus disease in cotton rats following immunization with Lot 100 or a newly prepared reference vaccine. J. Gen. Virol. 2001, 82, 2881-2888.

38. Chu, V.T.; Frohlich, A.; Steinhauser, G.; Scheel, T.; Roch, T.; Fillatreau, S.; Lee, J.J.; Lohning, M.; Berek, C. Eosinophils are required for the maintenance of plasma cells in the bone marrow. Nat. Immunol. 2011, 12, 151-159.

39. Olson, M.R.; Varga, S.M. CD8 T cells inhibit respiratory syncytial virus (RSV) vaccineenhanced disease. J. Immunol. 2007, 179, 5415-5424.

40. Power, U.F.; Plotnicky, H.; Blaecke, A.; Nguyen, T.N. The immunogenicity, protective efficacy and safety of BBG2Na, a subunit respiratory syncytial virus (RSV) vaccine candidate, against RSV-B. Vaccine 2003, 22, 168-176.

41. Graham, B.S. Biological challenges and technological opportunities for respiratory syncytial virus vaccine development. Immunol. Rev. 2011, 239, 149-166. 
42. McLellan, J.S. F Protein Structures and Their Implications for Humoral Immunity. Presented at the 8th Respiratory Syncytial Virus Symposium, Santa Fe, NM, 2012.

43. Fishaut, M.; Tubergen, D.; McIntosh, K. Cellular response to respiratory viruses with particular reference to children with disorders of cell-mediated immunity. J. Pediatr. 1980, 96, 179-186.

44. Hall, C.B.; Powell, K.R.; MacDonald, N.E.; Gala, C.L.; Menegus, M.E.; Suffin, S.C.; Cohen, H.J. Respiratory syncytial viral infection in children with compromised immune function. N. Engl. J Med. 1986, 315, 77-81.

45. Phipps, S.; Lam, C.E.; Mahalingam, S.; Newhouse, M.; Ramirez, R.; Rosenberg, H.F.; Foster, P.S.; Matthaei, K.I. Eosinophils contribute to innate antiviral immunity and promote clearance of respiratory syncytial virus. Blood 2007, 110, 1578-1586.

46. Welliver, R.C., Sr. The immune response to respiratory syncytial virus infection: friend or foe? Clin. Rev. Allergy Immunol. 2008, 34, 163-173.

47. DeVincenzo, J.; Lambkin-Williams, R.; Wilkinson, T.; Cehelsky, J.; Nochur, S.; Walsh, E.; Meyers, R.; Gollob, J.; Vaishnaw, A. A randomized, double-blind, placebo-controlled study of an RNAi-based therapy directed against respiratory syncytial virus. Proc. Natl. Acad. Sci. USA 2010, 107, 8800-8805.

48. Rudraraju, R.; Surman, S.L.; Jones, B.G.; Sealy, R.; Woodland, D.L.; Hurwitz, J.L. Reduced frequencies and heightened CD103 expression among virus-induced CD8(+) T cells in the respiratory tract airways of vitamin A-deficient mice. Clin. Vaccine Immunol. 2012, 19, 757-765.

49. Surman, S.L.; Rudraraju, R.; Sealy, R.; Jones, B.; Hurwitz, J.L. Vitamin A deficiency disrupts vaccine-induced antibody-forming cells and the balance of $\operatorname{IgA} / \operatorname{IgG}$ isotypes in the upper and lower respiratory tract. Viral Immunol. 2012, 25, 341-344.

50. Falsey AR. RSV in adults: What do we know? What do we need to know? Where are we going?, Proceedings of the 7th International Respiratory Syncytial Virus Symposium, Rotterdam, The Netherlands, 2 December 2010.

51. Graham, B.S. Future of RSV vaccine development. Presented at the 8th Respiratory Syncytial Virus Symposium, Santa Fe, NM, USA, 2012.

52. Moss, B. Smallpox vaccines: Targets of protective immunity. Immunol. Rev. 2011, 239, 8-26.

53. Murphy, K.; Travers, P.; Walport, M. Janeway's Immunobiology, 7 Edition; Garland Science: New York, NY, USA, 2008.

54. Peters, A.; Lee, Y.; Kuchroo, V.K. The many faces of Th17 cells. Curr. Opin. Immunol. 2011, 23, 702-706.

55. Kelso, A. Th1 and Th2 subsets: Paradigms lost? Immunol. Today 1995, 16, 374-379.

56. Mosmann, T.R.; Cherwinski, H.; Bond, M.W.; Giedlin, M.A.; Coffman, R.L. Two types of murine helper $\mathrm{T}$ cell clone. I. Definition according to profiles of lymphokine activities and secreted proteins. J. Immunol. 1986, 136, 2348-2357.

57. Crotty, S. Follicular helper CD4 T cells (TFH). Annu. Rev. Immunol. 2011, 29, 621-663.

58. Crotty, S.; Felgner, P.; Davies, H.; Glidewell, J.; Villarreal, L.; Ahmed, R. Cutting edge: Long-term B cell memory in humans after smallpox vaccination. $J$ Immunol. 2003, $171,4969-4973$. 
59. Lerch, R.A.; Anderson, K.; Amann, V.L.; Wertz, G.W. Nucleotide sequence analysis of the bovine respiratory syncytial virus fusion protein mRNA and expression from a recombinant vaccinia virus. Virology 1991, 181, 118-131.

60. Schmidt, A.C.; McAuliffe, J.M.; Murphy, B.R.; Collins, P.L. Recombinant bovine/human parainfluenza virus type 3 (B/HPIV3) expressing the respiratory syncytial virus (RSV) $\mathrm{G}$ and $\mathrm{F}$ proteins can be used to achieve simultaneous mucosal immunization against RSV and HPIV3. J. Virol. 2001, 75, 4594-4603.

61. Stevens, W.W.; Sun, J.; Castillo, J.P.; Braciale, T.J. Pulmonary eosinophilia is attenuated by early responding CD8(+) memory $\mathrm{T}$ cells in a murine model of RSV vaccine-enhanced disease. Viral Immunol. 2009, 22, 243-251.

62. Jones, B.; Zhan, X.; Mishin, V.; Slobod, K.S.; Surman, S.; Russell, C.J.; Portner, A.; Hurwitz, J.L. Human PIV-2 recombinant Sendai virus (rSeV) elicits durable immunity and combines with two additional rSeVs to protect against hPIV-1, hPIV-2, hPIV-3, and RSV. Vaccine 2009, 27, 1848-1857.

63. Zhan, X.; Slobod, K.S.; Krishnamurthy, S.; Luque, L.E.; Takimoto, T.; Jones, B.; Surman, S.; Russell, C.J.; Portner, A.; Hurwitz, J.L. Sendai virus recombinant vaccine expressing hPIV-3 HN or $\mathrm{F}$ elicits protective immunity and combines with a second recombinant to prevent hPIV-1, hPIV-3 and RSV infections. Vaccine 2008, 26, 3480-3488.

64. Crowe, J.E., Jr.; Randolph, V.; Murphy, B.R. The live attenuated subgroup B respiratory syncytial virus vaccine candidate RSV $2 \mathrm{~B} 33 \mathrm{~F}$ is attenuated and immunogenic in chimpanzees, but exhibits partial loss of the ts phenotype following replication in vivo. Virus Res. 1999, 59, 13-22.

65. De, W.L.; Power, U.F.; Yuksel, S.; Van, A.G.; Nguyen, T.N.; Niesters, H.G.; de Swart, R.L.; Osterhaus, A.D. Evaluation of BBG2Na in infant macaques: specific immune responses after vaccination and RSV challenge. Vaccine 2004, 22, 915-922.

66. Jones, B.G.; Sealy, R.E.; Rudraraju, R.; Traina-Dorge, V.L.; Finneyfrock, B.; Cook, A.; Takimoto, T.; Portner, A.; Hurwitz, J.L. Sendai virus-based RSV vaccine protects African green monkeys from RSV infection. Vaccine 2012, 30, 959-968.

67. Karron, R.A.; Wright, P.F.; Crowe, J.E., Jr.; Clements-Mann, M.L.; Thompson, J.; Makhene, M.; Casey, R.; Murphy, B.R. Evaluation of two live, cold-passaged, temperature-sensitive respiratory syncytial virus vaccines in chimpanzees and in human adults, infants, and children. J. Infect. Dis. 1997, 176, 1428-1436.

68. Friedewald, W.T.; Forsyth, B.R.; Smith, C.B.; Gharpure, M.A.; Chanock, R.M. Low-temperature-grown RS virus in adult volunteers. JAMA 1968, 204, 690-694.

69. Schickli, J.H.; Kaur, J.; Tang, R.S. Nonclinical phenotypic and genotypic analyses of a Phase 1 pediatric respiratory syncytial virus vaccine candidate MEDI-559 (rA2cp248/404/1030DeltaSH) at permissive and non-permissive temperatures. Virus Res. 2012, 169, 38-47.

70. Wright, P.F.; Karron, R.A.; Belshe, R.B.; Thompson, J.; Crowe, J.E., Jr.; Boyce, T.G.; Halburnt, L.L.; Reed, G.W.; Whitehead, S.S.; Anderson, E.L.; et al. Evaluation of a live, coldpassaged, temperature-sensitive, respiratory syncytial virus vaccine candidate in infancy. J. Infect. Dis. 2000, 182, 1331-1342. 
71. Firestone, C.Y.; Whitehead, S.S.; Collins, P.L.; Murphy, B.R.; Crowe, J.E., Jr. Nucleotide sequence analysis of the respiratory syncytial virus subgroup A cold-passaged (cp) temperature sensitive (ts) cpts-248/404 live attenuated virus vaccine candidate. Virology 1996, 225, 419-422.

72. Karron, R.A.; Wright, P.F.; Belshe, R.B.; Thumar, B.; Casey, R.; Newman, F.; Polack, F.P.; Randolph, V.B.; Deatly, A.; Hackell, J.; Identification of a recombinant live attenuated respiratory syncytial virus vaccine candidate that is highly attenuated in infants. J. Infect. Dis. 2005, 191, 1093-1104.

73. Buchholz, U.J.; Luongo, C.; Winter, C.C.; Tang, R.S.; Karron, R.A.; Schickli, J.H.; Collins, P.L. Live-Attenuated RSV Vaccine Candidates for Clinical Studies: Improving Genetic Stability and Backup Plans. Presented at the 8th Respiratory Syncytial Virus Symposium, Santa Fe, NM, USA, 2012.

74. Luongo, C.; Winter, C.C.; Collins, P.L.; Buchholz, U.J. Respiratory syncytial virus modified by deletions of the NS2 gene and amino acid S1313 of the L polymerase protein is a temperature sensitive live-attenuated vaccine candidate that is phenotypically stable at physiological temperature. J Virol 2012, 87, 1985-96.

75. Nagai, Y.; Kato, A. Paramyxovirus reverse genetics is coming of age. Microbiol. Immunol. 1999, $43,613-624$.

76. Jin, H.; Zhou, H.; Cheng, X.; Tang, R.; Munoz, M.; Nguyen, N. Recombinant respiratory syncytial viruses with deletions in the NS1, NS2, SH, and M2-2 genes are attenuated in vitro and in vivo. Virology 2000, 273, 210-218.

77. Cheng, X.; Zhou, H.; Tang, R.S.; Munoz, M.G.; Jin, H. Chimeric subgroup A respiratory syncytial virus with the glycoproteins substituted by those of subgroup B and RSV without the M2-2 gene are attenuated in African green monkeys. Virology 2001, 283, 59-68.

78. Schepens, B.; De Baets, S.; Sedyen, K.; Bogaert, P.; Gilbert, B.; Piedra, P.A.; Fiers, W.; Saelens, X. SHe's a novel target for RSV vaccination. Presented at the 8th Respiratory Syncytial Virus Symposium, Santa Fe, NM, USA, 2012.

79. Swanson, K.A.; Settembre, E.C.; Shaw, C.A.; Dey, A.K.; Rappuoli, R.; Mandl, C.W.; Dormitzer, P.R.; Carfi, A. Structural basis for immunization with postfusion respiratory syncytial virus fusion F glycoprotein (RSV F) to elicit high neutralizing antibody titers. Proc. Natl. Acad. Sci. USA 2011, 108, 9619-9624.

80. Zhang, W.; Choi, Y.; Haynes, L.M.; Harcourt, J.L.; Anderson, L.J.; Jones, L.P.; Tripp, R.A. Vaccination to induce antibodies blocking the CX3C-CX3CR1 interaction of respiratory syncytial virus $\mathrm{G}$ protein reduces pulmonary inflammation and virus replication in mice. J. Virol. 2010, 84, 1148-1157.

81. Sealy, R.; Chaka, W.; Surman, S.; Brown, S.A.; Cresswell, P.; Hurwitz, J.L. Target peptide sequence within infectious human immunodeficiency virus type 1 does not ensure envelopespecific T-helper cell reactivation: influences of cysteine protease and gamma interferon-induced thiol reductase activities. Clin. Vaccine Immunol. 2008, 15, 713-719.

82. Colman, P.M.; Laver, W.G.; Varghese, J.N.; Baker, A.T.; Tulloch, P.A.; Air, G.M.; Webster, R.G. Three-dimensional structure of a complex of antibody with influenza virus neuraminidase. Nature 1987, 326, 358-363. 
83. Arnold, P.Y.; La Gruta, N.L.; Miller, T.; Vignali, K.M.; Adams, P.S.; Woodland, D.L.; Vignali, D.A. The majority of immunogenic epitopes generate CD4+ T cells that are dependent on MHC class II-bound peptide-flanking residues. J. Immunol. 2002, 169, 739-749.

84. Moudgil, K.D.; Sercarz, E.E.; Grewal, I.S. Modulation of the immunogenicity of antigenic determinants by their flanking residues. Immunol. Today 1998, 19, 217-220.

85. Correia, B.E.; Bates, J.T.; Loomis, R.; Connell, M.J.; Baneyx, G.; Jardine, J.G.; Rupert, P.; Correnti, C.; Vittal, V.; Kalyuzhniy, O.; et al. A Computationally Designed Experimental RSV F Protein Epitope Vaccine that Induces Potent Neutralizing Antibodies in Nonhuman Primates. Presented at the 8th Respiratory Syncytial Virus Symposium, Santa Fe, NM, USA, 2012.

86. Makidon, P.E.; Bitko, V.; Simon, J.K.; Lukacs, N.W.; Hamouda, T.; O'Konek, J.J.; Fattom, A.; Baker, J.R., Jr. Immunogenicity and Efficacy of Line 19 RSV Vaccine in Cotton Rats. Presented at the 8th Respiratory Syncytial Virus Symposium, Santa Fe, NM, 2012.

87. Grasso, S.; Santi, L. Viral nanoparticles as macromolecular devices for new therapeutic and pharmaceutical approaches. Int. J. Physiol. Pathophysiol. Pharmacol. 2010, 2, 161-178.

88. Garg, R.; Brownlie, R.; Latimer, L.; Connor, W.; Simko, E.; Gerdts, V.; Babiuk, L.A.; Potter, A.; van Drunen Littel-van den Hurk, S. Intranasal immunization with the RSV fusion protein formulated with novel combination adjuvants induces protective immunity. Presented at the 8th Respiratory Syncytial Virus Symposium, Santa Fe, NM, USA, 2012.

89. Garlapati, S.; Garg, R.; Brownlie, R.; Latimer, L.; Simko, E.; Hancock, R.E.; Babiuk, L.A.; Gerdts, V.; Potter, A.; van Drunen Littel-van den Hurk. Enhanced immune responses and protection by vaccination with respiratory syncytial virus fusion protein formulated with $\mathrm{CpG}$ oligodeoxynucleotide and innate defense regulator peptide in polyphosphazene microparticles. Vaccine 2012, 30, 5206-5214.

90. Glenn, G.M.; Smith, G.; Raghunandan, R.; Li, H.; Zhou, B.; Thomas, D.N.; Fries, L. Immunogenicity of an Sf9 insect cell-derived respiratory syncytial virus fusion protein nanoparticle vaccine: Insights into pathogenicity. Presented at the 8th Respiratory Syncytial Virus Symposium, Santa Fe, NM, USA, 2012.

91. Smith, G.; Raghunandan, R.; Wu, Y.; Liu, Y.; Massare, M.; Nathan, M.; Zhou, B.; Lu, H.; Boddapati, S.; Li, J.; Respiratory syncytial virus fusion glycoprotein expressed in insect cells form protein nanoparticles that induce protective immunity in cotton rats. PLoS One 2012, 7, e50852.

92. Simoes, E.A.; Groothuis, J.R.; Carbonell-Estrany, X.; Rieger, C.H.; Mitchell, I.; Fredrick, L.M.; Kimpen, J.L. Palivizumab prophylaxis, respiratory syncytial virus, and subsequent recurrent wheezing. J. Pediatr. 2007, 151, 34-42.

93. Kamphuis, T.; Meijerhof, T.; Stegmann, T.; Lederhofer, J.; Wilschut, J.; de, H.A. Immunogenicity and protective capacity of a virosomal respiratory syncytial virus vaccine adjuvanted with monophosphoryl lipid A in mice. PLoS One 2012, 7, e36812.

94. Bernstein, D.I.; Malkin, E.; Abughali, N.; Falloon, J.; Yi, T.; Dubovsky, F. Phase 1 study of the safety and immunogenicity of a live, attenuated respiratory syncytial virus and parainfluenza virus type 3 vaccine in seronegative children. Pediatr. Infect. Dis. J. 2012, 31, 109-114.

95. Tang, R.S.; Spaete, R.R.; Thompson, M.W.; MacPhail, M.; Guzzetta, J.M.; Ryan, P.C.; Reisinger, K.; Chandler, P.; Hilty, M.; Walker, R.E.; et al. Development of a PIV-vectored RSV 
vaccine: Preclinical evaluation of safety, toxicity, and enhanced disease and initial clinical testing in healthy adults. Vaccine 2008, 26, 6373-6382.

96. Tang, R.S.; MacPhail, M.; Schickli, J.H.; Kaur, J.; Robinson, C.L.; Lawlor, H.A.; Guzzetta, J.M.; Spaete, R.R.; Haller, A.A. Parainfluenza virus type 3 expressing the native or soluble fusion (F) Protein of Respiratory Syncytial Virus (RSV) confers protection from RSV infection in African green monkeys. J. Virol. 2004, 78, 11198-11207.

97. Tang, R.S.; Malkin, E.; Stillman, E.; Nelson, C.; Yang, C.-F.; Song, E.; Liang, B.; Shambaugh, C.; Zuo, F.; Liem, A.; et al. Implication of genetic changes observed in Phase 1 evaluation of MEDI-534, a live attenuated chimeric bovine human parainfluenza type 3 vectored RSV vaccine. Presented at the 8th Respiratory Syncytial Virus Symposium, Santa Fe, NM, USA 2012.

98. Power, U.F.; Ryan, K.W.; Portner, A. Sequence characterization and expression of the matrix protein gene of human parainfluenza virus type 1. Virology 1992, 191, 947-952.

99. Lyn, D.; Gill, D.S.; Scroggs, R.A.; Portner, A. The nucleoproteins of human parainfluenza virus type 1 and Sendai virus share amino acid sequences and antigenic and structural determinants. J. Gen. Vir. 1991, 72, 983-987.

100. Sangster, M.; Smith, F.S.; Coleclough, C.; Hurwitz, J.L. Human parainfluenza virus-type 1 immunization of infant mice protects from subsequent Sendai virus infection. Virology 1995, 212, 13-19.

101. Dave, V.P.; Allan, J.E.; Slobod, K.S.; Smith, S.F.; Ryan, K.; Powell, U.; Portner, A.; Hurwitz, J.L. Viral cross-reactivity and antigenic determinants recognized by human parainfluenza virus type 1-specific cytotoxic T-cells. Virology 1994, 199, 376-383.

102. Smith, F.S.; Portner, A.; Leggiadro, R.J.; Turner, E.V.; Hurwitz, J.L. Age-related development of human memory T-helper and B-cell responses toward parainfluenza virus type-1. Virology 1994, 205, 453-461.

103. Bousse, T.; Chambers, R.L.; Scroggs, R.A.; Portner, A.; Takimoto, T. Human parainfluenza virus type 1 but not Sendai virus replicates in human respiratory cells despite IFN treatment. Virus Res. 2006, 121, 23-32.

104. Zhan, X.; Hurwitz, J.L.; Krishnamurthy, S.; Takimoto, T.; Boyd, K.; Scroggs, R.A.; Surman, S.; Portner, A.; Slobod, K.S. Respiratory syncytial virus (RSV) fusion protein expressed by recombinant Sendai virus elicits B-cell and T-cell responses in cotton rats and confers protection against RSV subtypes A and B. Vaccine 2007, 25, 8782-8793.

105. Slobod, K.S.; Shenep, J.L.; Lujan-Zilbermann, J.; Allison, K.; Brown, B.; Scroggs, R.A.; Portner, A.; Coleclough, C.; Hurwitz, J.L. Safety and immunogenicity of intranasal murine parainfluenza virus type 1 (Sendai virus) in healthy human adults. Vaccine 2004, 22, 3182-3186.

106. Chen, M.; Hu, K.F.; Rozell, B.; Orvell, C.; Morein, B.; Liljestrom, P. Vaccination with recombinant alphavirus or immune-stimulating complex antigen against respiratory syncytial virus. J. Immunol. 2002, 169, 3208-3216.

107. Mok, H.; Lee, S.; Utley, T.J.; Shepherd, B.E.; Polosukhin, V.V.; Collier, M.L.; Davis, N.L.; Johnston, R.E.; Crowe, J.E., Jr. Venezuelan equine encephalitis virus replicon particles encoding respiratory syncytial virus surface glycoproteins induce protective mucosal responses in mice and cotton rats. J. Virol. 2007, 81, 13710-13722. 
108. Elliott, M.B.; Chen, T.; Terio, N.B.; Chong, S.Y.; Abdullah, R.; Luckay, A.; Egan, M.A.; Boutilier, L.A.; Melville, K.; Lerch, R.A.; et al. Alphavirus replicon particles encoding the fusion or attachment glycoproteins of respiratory syncytial virus elicit protective immune responses in $\mathrm{BALB} / \mathrm{c}$ mice and functional serum antibodies in rhesus macaques. Vaccine 2007, 25, 7132-7144.

109. Kohlmann, R.; Schwannecke, S.; Tippler, B.; Ternette, N.; Temchura, V.V.; Tenbusch, M.; Uberla, K.; Grunwald, T. Protective efficacy and immunogenicity of an adenoviral vector vaccine encoding the codon-optimized $\mathrm{F}$ protein of respiratory syncytial virus. J. Virol. 2009, 83, 12601-12610.

110. Johnson, T.R.; Rangel, D.; Liao, G.; Eastman, E.M.; Gall, J.G. Induction of Broadly Neutralizing Humoral Responses by Immunization with Respiratory Syncytial Virus F Expressing Adenovirus Vectors. Presented at the 8th Respiratory Syncytial Virus Symposium, Santa Fe, NM, USA, 2012.

111. De Baets, S.; Schepens, B.; Sedeyn, K.; Schotsaert, M.; Bogaert, P.; Fiers, W.; Saelens, X. Recombinant influenza virus carrying an RSV CTL epitope protects mice against respiratory syncytial virus infection. Presented at the 8th Respiratory Syncytial Virus Symposium, Santa Fe, NM, USA, 2012.

112. Sawada, A.; Komase, K.; Nakayama, T. AIK-C measles vaccine expressing fusion protein of respiratory syncytial virus induces protective antibodies in cotton rats. Vaccine 2011, $29,1481-1490$.

113. McGinnes, L.W.; Gravel, K.A.; Finberg, R.W.; Kurt-Jones, E.A.; Massare, M.J.; Smith, G.; Schmidt, M.R.; Morrison, T.G. Assembly and immunological properties of Newcastle disease virus-like particles containing the respiratory syncytial virus $\mathrm{F}$ and $\mathrm{G}$ proteins. J. Virol. 2011, 85, 366-377.

114. Andersson, C.; Liljestrom, P.; Stahl, S.; Power, U.F. Protection against respiratory syncytial virus (RSV) elicited in mice by plasmid DNA immunisation encoding a secreted RSV G protein-derived antigen. FEMS Immunol. Med. Microbiol. 2000, 29, 247-253.

115. Hurwitz, J.L. Respiratory syncytial virus vaccine development. Expert. Rev. Vaccines 2011, 10, 1415-1433.

116 Lau, J.M.; Korban, S.S. Transgenic apple expressing an antigenic protein of the human respiratory syncytial virus. J. Plant Physiol. 2010, 167, 920-927.

117. Haijema, B.J.; Leenhouts, K.; Widjaja, I.; Rigter, A.; De Haan, X.; Rottier, P. Intranasal administration of bacterium-like particles carrying RSV F antigen (SynGEM) induces a safe and protective RSV-specific immune response. Presented at the 8th Respiratory Syncytial Virus Symposium, Santa Fe, NM, USA, 2012.

118. Taylor, G.; Thom, M.; Herbert, B.; Pierantoni, A.; Capone, S.; Nicosia, A.; Vitelli, A. Novel replication-defective chimpanzee adenovirus (ChAD) and modified vaccinia Ankara (MVA) vectors expressing human (H)RSV antigens protect calves against BRSV infection. Presented at the 8th Respiratory Syncytial Virus Symposium, Santa Fe, NM, USA, 2012. 
119. Grunwald, T.; Tenbusch, M.; Schulte, R.; Franz, M.; Hannaman, D.; Tippler, B.; de Swart, R.L.; Steinman, R.; Stahl-Hennig, C.; Uberla, K. Immunogenicity and efficacy of genetic RSV vaccines in rhesus monkeys. Presented at the 8th Respiratory Syncytial Virus Symposium, Santa Fe, NM, USA, 2012.

120. Shafique, M.; Wilschut, J.; de, H.A. Induction of mucosal and systemic immunity against respiratory syncytial virus by inactivated virus supplemented with TLR9 and NOD2 ligands. Vaccine 2012, 30, 597-606.

121. Stegmann, T.; Kamphuis, T.; Meijerhof, T.; Goud, E.; de, H.A.; Wilschut, J. Lipopeptide-adjuvanted respiratory syncytial virus virosomes: $\mathrm{A}$ safe and immunogenic non-replicating vaccine formulation. Vaccine 2010, 28, 5543-5550.

122. Murawski, M.R.; McGinnes, L.W.; Finberg, R.W.; Kurt-Jones, E.A.; Massare, M.J.; Smith, G.; Heaton, P.M.; Fraire, A.E.; Morrison, T.G. Newcastle disease virus-like particles containing respiratory syncytial virus $G$ protein induced protection in BALB/c mice, with no evidence of immunopathology. J. Virol. 2010, 84, 1110-1123.

123. Cautivo, K.M.; Bueno, S.M.; Cortes, C.M.; Wozniak, A.; Riedel, C.A.; Kalergis, A.M. Efficient lung recruitment of respiratory syncytial virus-specific Th1 cells induced by recombinant bacillus Calmette-Guerin promotes virus clearance and protects from infection. J. Immunol. 2010, 185, 7633-7645.

124. Xie, C.; He, J.S.; Zhang, M.; Xue, S.L.; Wu, Q.; Ding, X.D.; Song, W.; Yuan, Y.; Li, D.L.; Zheng, X.X.; et al. Oral respiratory syncytial virus (RSV) DNA vaccine expressing RSV F protein delivered by attenuated Salmonella typhimurium. Hum. Gene Ther. 2007, 18, 746-752.

125. Falcone, V.; Mihm, D.; Neumann-Haefelin, D.; Costa, C.; Nguyen, T.; Pozzi, G.; Ricci, S. Systemic and mucosal immunity to respiratory syncytial virus induced by recombinant Streptococcus gordonii surface-displaying a domain of viral glycoprotein G. FEMS Immunol. Med. Microbiol. 2006, 48, 116-122.

126. Schickli, J.H.; Dubovsky, F.; Tang, R.S. Challenges in developing a pediatric RSV vaccine. Hum. Vaccin. 2009, 5, 582-591.

(C) 2013 by the authors; licensee MDPI, Basel, Switzerland. This article is an open access article distributed under the terms and conditions of the Creative Commons Attribution license (http://creativecommons.org/licenses/by/3.0/). 